\title{
Primary spinal cord oligodendroglioma: a case report and review of the literature
}

\author{
Thara Tunthanathip ${ }^{*}$ and Thakul Oearsakul
}

\begin{abstract}
Background: Primary spinal cord oligodendroglioma is extremely rare. In an extensive review of this disease, 53 cases were reported. Furthermore, the authors summarize the characteristics of the primary spinal cord oligodendroglioma; chronological presentation, neurological imaging, treatment and the outcome obtained in the present case as well as review the literature.

Case Presentation: A 46-year-old male who had progressive neck pain for a year. Magnetic resonance imaging showed an intramedullary mass from level C2 to T4. A radical resection was performed. Histology revealed oligodendroglioma. Thereafter, the patient was treated with adjuvant radiotherapy. A year later, tumor developed recurrence. The patinet died in 3 years and 6 months.

Conclusions: The available data of this disease was limited. Base on 11 published papers and the present case, surgical resection is the treatment of choice although recurrence of the tumor tends to occur after partial resection with or without radiotherapy. From the literature, the management of the recurrent disease is still surgery. Moreover, Temozolomide may be an advantage in recurrent situations.
\end{abstract}

Keywords: Oligodendroglioma, Spinal cord tumor, Intramedullary tumor, Treatment

\section{Background}

Oligodendroglioma originates from oligodendrocyte, which is found in either the brain or spinal cord [1]. This tumor is commonly found in the cerebral hemisphere while both primary and drop metastasis spinal oligodendroglioma are an unusual presentation of a disease $[2,3]$. The lack of clinical information means there is no standard treatment in current practice. The authors report a case and review modality of treatment and prognosis from the literature.

\section{Case presentation}

A 46-year-old male was presented with progressive neck pain for a year. The symptoms began without any antecedent event. The symptoms were worse for 5 months. One month before admission, the patient developed left arm weakness and numbness in both arms. However, he had no urinary incontinence. Physical examination demonstrated grade 4/5 muscle weakness in the left arm. Other extremities revealed grade $5 / 5$ of motor strength.

\footnotetext{
* Correspondence: tsus4@hotmail.com

Neurosurgical Unit, Department of Surgery, Faculty of Medicine, Prince of Songkla University, Hat Yai, Songkhla 90110, Thailand
}

Pinpricked sensation was suspended deficits at C5-T1 levels. Biceps, triceps and brachioradialis, knee and Achilles reflexes were 2+. Further, Hoffman reflexes were absent.

Magnetic resonance imaging (MRI) of the spine showed an intramedullary mass $12.5 \mathrm{~cm}$ long from $\mathrm{C} 2$ to T4 level. The mass was isointense on T1-weighted images, hyperintense on T2-weighted images. Gadolinium-enhanced MRI demonstrated a heterogenous intramedullary mass. Additionally, syringomyelia was observed above the tumor on T2-weighted images (Fig. 1).

The patient was operated on under general anesthesia. Laminectomies were performed. A dural incision was made. The arachnoid was opened and secured with dural edges by $4 / 0$ prolene sutures. Expansion of the spinal cord was observed. A dorsal midline myelotomy approach was performed. A redness tumor was identified. The characteristics of the tumor were gelatinous, and infiltrative. Tumor dissection was done with difficultly and tumor bleeding was observed during the dissection (Fig. 2, Additional file 1). The tumor was partially removed using microsurgical techniques. After surgery, the neurological deficits were stable. Postoperative 


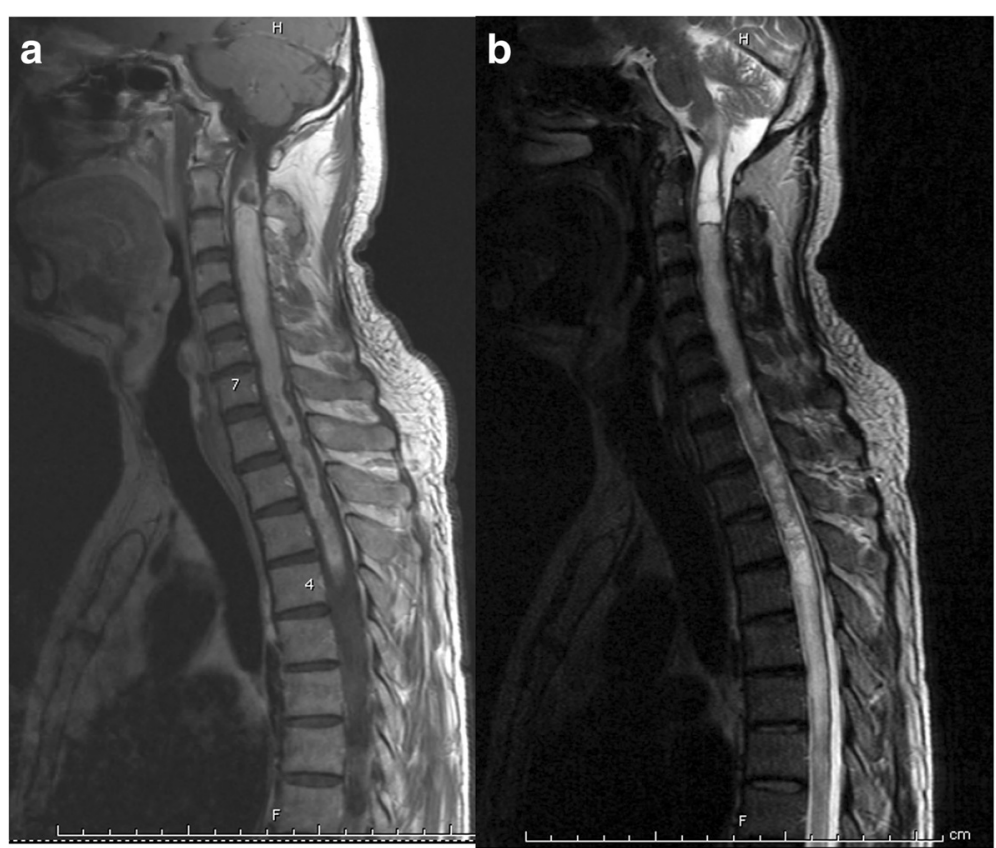

Fig. 1 An MRI of the cervicothoracic spinal cord. Gadolinium-enhanced sagittal T1-weighted image (a) showed an enhanced intramedullary tumor from C2 to T4 level. Sagittal T2-weighted image (b) showed syringomyelia above tumor

MRI revealed some amount of residual tumor remained in place and an improvement of syringomyelia.

Histologically, the tumor consisted of a fried egg appearance neoplastic cell, with a uniformly round nuclei and clear cytoplasm. Immunochemistry showed positive for glial fibrillary acidic protein (GFAP). On the basis of these findings, the tumor was diagnosed oligodendroglioma (Fig. 3).

After diagnosis, the patient was sent for an MRI of the brain. Imaging demonstrated no intracranial tumor (Fig. 4). Two weeks later, the patient received postoperative radiotherapy ( $45 \mathrm{~Gy} / 25$ fractions). Twelve months after resection, the patient rapidly developed urinary incontinence and paraplegia. On neurological examination, his muscle power was grade $0 / 5$ in both upper and lower limbs. Furthermore, loose sphincter tone and hyperreflexia of all extremities were detected. MRI of the spine revealed recurrence of tumor with extension to the previous surgical wound (Fig. 5). A secondary operation was considered, but the patient and his relatives denied surgery. Unfortunately, he died in 3 years and 6 months after surgery.

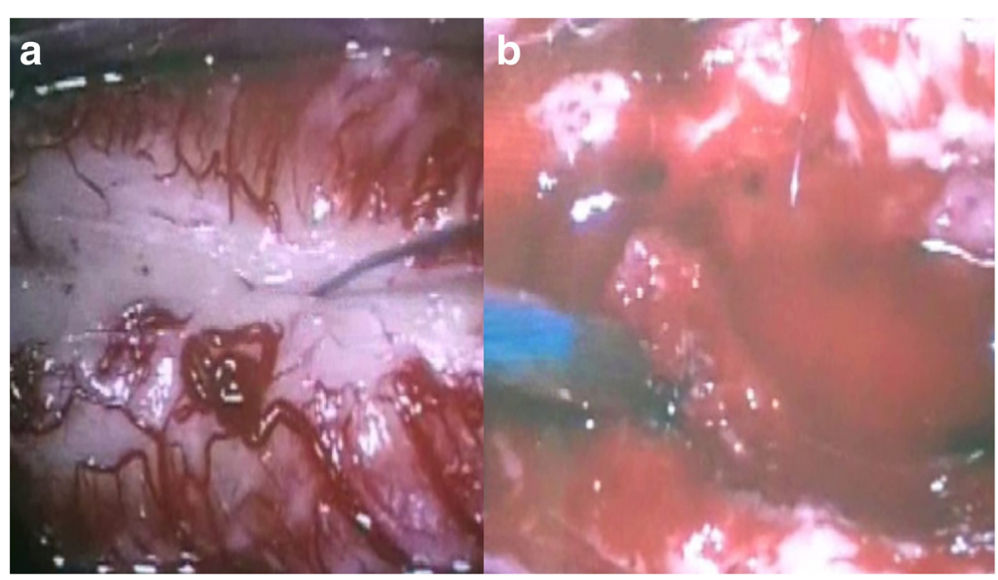

Fig. 2 A photograph of an intraoperative finding. Posterior midline myelotomy (a) was done on expanding the spinal cord. An intramedullary tumor at the tip of suction (b) was gelatinous, reddish in color and difficult to discriminate from spinal cord 


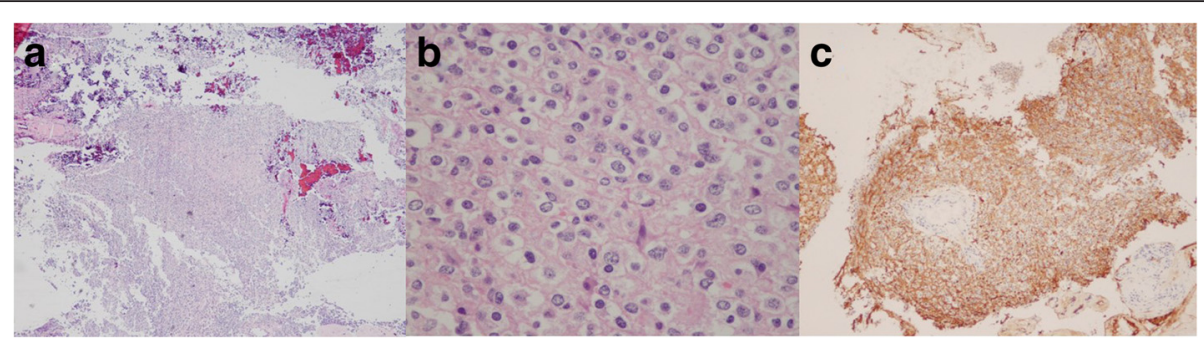

Fig. 3 Photomicrographs of the intramedullary specimen. Hematoxylin and eosin stain with original magnification (a) showed a sheet of a highly cellular tumor. At 400 times magnification (b), tumor cells consisted of hyperchromatic nuclei and clear cytoplasm as a fried egg appearance. Glial fibrillary acidic protein stain (c) with 100 times magnification showed marked positive immunoreactivity

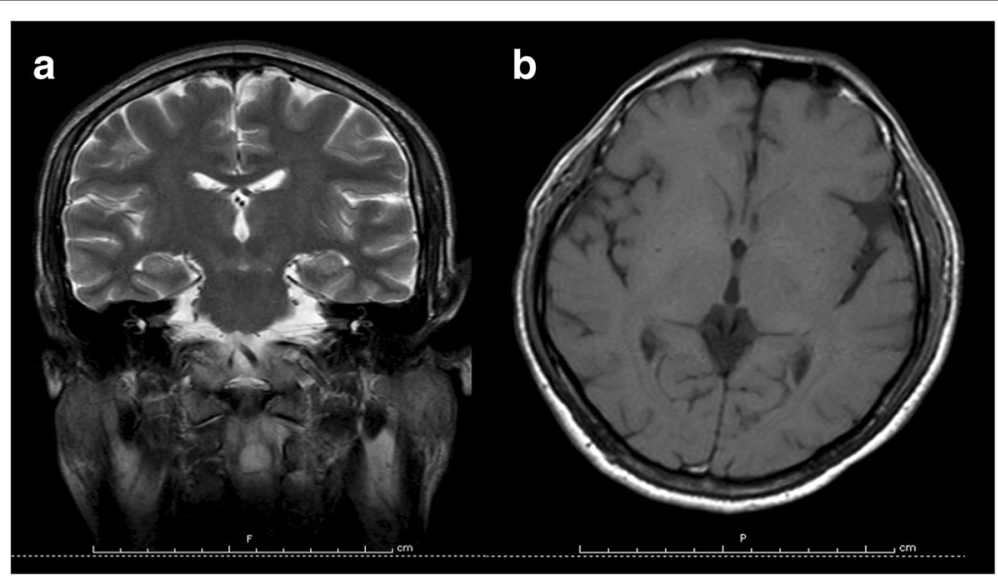

Fig. 4 An MRI of the brain. Coronal T2-weighted (a) and axial T1-weighted image (b) showed no intracranial tumor

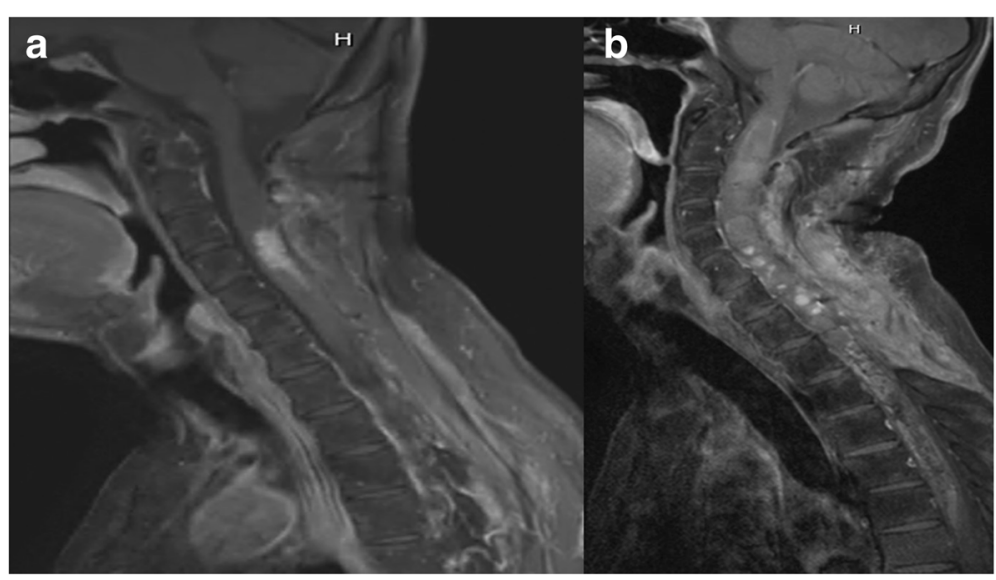

Fig. 5 Gadolinium-enhanced sagittal T1-weighted image of the spine at 3 months (a) and 12 months (b) postoperatively showed a small residual tumor located the C3-5 level and tumor recurrence surrounding previous surgical field respectively 


\section{Discussion}

Oligodendrocytes are the myelination cells of the brain and spinal cord. In the spinal cord, most oligodendrocyte derived from oligodendrocyte precursor cells at the ventral ventricular zone, which migrate through the spinal cord and differentiate into oligodendrocytes [1]. Oligodendrogliomas are one of the primary brain tumors usually occurring in the cerebral hemispheres while these tumors of the spinal cord are rare. To the authors' knowledge, only 53 cases have been reported in literature [4-19].

In 1980, Fortuna et al. reported the landmark paper that collected all the previously reported 37 patients in table [4]. Guidetti et al. reported one case in a large clinical series of 129 intramedullary tumors [5]. Alvisi et al. reported two other cases in 1984 [6]. Additionally, Pagni et al. reported a "holocord" type of primary spinal oligodendroglioma that was located from craniocervical junction to the conus in 1991 [7]. Wang et al. reported another pediatric case in 1993 [8]. Later in 1994, Cristante et al. reported another case [9]. Constantini et al. reported one case a few years later [10]. Nam et al. [11] presented intramedullary anaplastic oligodendroglioma in a child in 1998. Therefore, Ushida et al. reported the widespread type of tumor that extended more than ten vertebral levels in 1998 [12]. Gilmer-Hill et al. reported a pediatric case with gliomatosis in 2000 [13]. Miller et al. and Aman et al. [14, 15] Later, found two patients with this type of tumor. Fountas et al. reported a case of anaplastic oligodendroglioma that was intradural extramedullary in 2005 [16]. The total numbers of spinal oligodendroglioma cases were 50 in 2005. A year later, Gürkanlar et al. published another case of intradural extramedullary tumor at L1-2 level [17]. Interestingly, Ramirez et al. reported a case of primary spinal anaplastic oligodendroglioma that developed a secondary brain metastasis 2 years after spinal surgery [18]. In 2011, Wang et al. reported a case of spinal anaplastic oligodendroglioma associated with $1 p$ deletion [19]. In summary, the number of cases was 53 in 2011. However, the available data of patients was limited. Base on 11 published papers and the present case, the authors reviewed the treatment and prognosis of cases in Table 1.

In literature, Ushida et al. reviewed the characteristics of patients with this tumor. The mean age was 28.4 years, no significant difference in sex [12]. Spinal pain that included back pain, buttock pain and sciatica was the most common first symptom for $69.3 \%$ whereas the most common symptom on physical examination was a sensorimotor deficit [4]. According to the location of spinal cord, these tumors have been found frequently in the thoracic (30\%), cervical (25\%) and lumbar (5\%) area respectively [16]. Furthermore, this disease frequently presented with an intramedullary lesion in the spinal canal. Intradural extramedullary was an unusual presentation $[16,17]$. Common spinal features on MRI's were isointense in T1-weighted images and hyperintense in T2-weighted images and heterogenous enhancement in Gadolinium-enhanced sagittal T1-weighted images [7, 12, 16-19]. Uncommon findings might be found as an adjacent cystic component [11-13], microhemorrhage $[4,16,19]$. Diagnosis of this disease are difficult to distinguish from other gliomas by MRI because these findings can find in spinal astrocytoma and ependymoma [20]. However, microcalcification is important finding, which mentioned oligodendroglioma similar to intracranial oligodendroglioma $[11,16]$. Regarding to histology, Most of the tumors are oligodendroglioma WHO grade 2. Wang et al. reviewed 8 cases, which were anaplastic oligodendroglioma in the literature and added a case [19].

From Table 1, surgical resection is the treatment of choice. Unfortunately, gross total resection is so difficult because almost all tumors are the intramedullary type. In the literature, gross total resection was achieved in only $16.6 \%(2 / 12)$ of the cases. Moreover, tumor recurrence was observed almost $42 \%(5 / 12)$ within 8 months to 2 years. Second operation was mentioned in recurrent situation with postoperative adjuvant therapy. The benefit of radiation therapy is still controversial. Nam et al. reported outcome of anaplastic oligodendroglioma, which was treated with partial tumor resection and postoperative radiation. The patient has no progression of residual tumor after 50 months follow up [8]. However, Ramirez et al. and Wang et al. were reported the patients whom are treated with partial tumor resection and postoperative radiation too $[18,19]$. Unfortunately, both patients have progressive disease.

The adjuvant chemotherapy has been mentioned to treat recurrent scenario [13, 19]. Temozolomide (TMZ) that is a novel alkylating and methylating agent has been reported the benefits in oligodendroglioma [21]. Adjuvant TMZ treatment has recently reported in relapse conditions. The patient who was operated in the second time received postoperative TMZ to treat the residual tumor. Complete resolution of the residual tumor within six months of TMZ chemotherapy was observed on MRI of the spine [19].

\section{Conclusions}

Primary spinal cord oligodendrogliomas are extremely rare tumors. In spite of limited data of treatment, surgical resection is the treatment of choice although recurrence of the tumor tends to occur after partial resection with or without radiotherapy. From the literature, the management of the recurrent disease is still surgery. 
Table 1 Review of the literature in the treatment and outcome of primary spinal cord oligodendroglioma

\begin{tabular}{|c|c|c|c|c|c|c|}
\hline $\begin{array}{l}\text { Authors/ } \\
\text { Year }\end{array}$ & $\begin{array}{l}\text { Age } \\
\text { (year)/ } \\
\text { Sex }\end{array}$ & Symptoms & Location & Histology & Treatment & Outcome \\
\hline $\begin{array}{l}\text { Fortuna } \\
\text { et al. [4] }\end{array}$ & $32 / F$ & LBP, paraparesis & T10-T11 & Oligo & $\mathrm{Bx}$ & NA \\
\hline $\begin{array}{l}\text { Guidetti } \\
\text { et al. [5] }\end{array}$ & $N A / F$ & NA & NA & Oligo & PR & 3 years, death \\
\hline $\begin{array}{l}\text { Pagni } \\
\text { et al. [7] }\end{array}$ & $13 / \mathrm{M}$ & $\begin{array}{l}\text { Kyphoscoliosis, painful } \\
\text { sensation involved at neck } \\
\text { and shoulder and tetraparesis }\end{array}$ & IM at C5-T2 & Oligo & PR & 2 years, improvement \\
\hline $\begin{array}{l}\text { Wang } \\
\text { et al. [8] }\end{array}$ & $3 / \mathrm{M}$ & Scoliosis & Thoracolumbar & $\mathrm{AO}$ & $P R$ and $R T$ & NA \\
\hline $\begin{array}{l}\text { Nam } \\
\text { et al. [11] }\end{array}$ & $38 / \mathrm{M}$ & $\begin{array}{l}\text { Scoliosis, and monoparesis of } \\
\text { right lower limb }\end{array}$ & $\begin{array}{l}\text { IM with syringomyelia } \\
\text { along T4-conus } \\
\text { medullaris }\end{array}$ & $\mathrm{AO}$ & PR and RT & 50 months, no progression of tumor \\
\hline $\begin{array}{l}\text { Ushida } \\
\text { et al. [12] }\end{array}$ & $12 / \mathrm{M}$ & $\begin{array}{l}\text { Scoliosis, hypesthesia of legs, } \\
\text { Hyperreflexia of legs }\end{array}$ & $\begin{array}{l}\text { IM with syringomyelia } \\
\text { at C7-T12 }\end{array}$ & Oligo & 1st PR & -10 months, recurrence of tumor-2nd PR and RT \\
\hline $\begin{array}{l}\text { Gilmer- } \\
\text { Hill et al. } \\
\text { [13] }\end{array}$ & $4 / \mathrm{M}$ & $\begin{array}{l}\text { Irritability, Hypotonia, ataxic } \\
\text { gait }\end{array}$ & $\begin{array}{l}\text { Primary intramedullary } \\
\text { oligodendroglioma at C6- } \\
\text { T1 with gliomatosis }\end{array}$ & Oligo & $\begin{array}{l}\text {-1st cerebellar, occipital Bx } \\
\text { (Spondgliform cerebellar } \\
\text { degeneration)-2nd temporal } \\
\text { Bx (Oligodendrogliomatosis)-3rd } \\
\text { spinal Bx (Oligodendroglioma) and CMT }\end{array}$ & $\begin{array}{l}-10 \text { months after CMT, recurrence at temporal lobe- } 4 \text { th PR and RT- } \\
\text { (AO)-4 months after RT, recurrence at occipital lobe-5th PR and } \\
\text { CMT (AO)-7 months after surgery, stable disease }\end{array}$ \\
\hline $\begin{array}{l}\text { Fountas } \\
\text { et al. [16] }\end{array}$ & $16 / F$ & $\begin{array}{l}\text { Neurogenic bladder, left ankle } \\
\text { weakness and sensory deficit } \\
\text { of S1 nerve root on the left. }\end{array}$ & $\begin{array}{l}\text { IDEM with extension } \\
\text { at T11-L2 }\end{array}$ & $\mathrm{AO}$ & TR & 28 months, no recurrence of tumor \\
\hline $\begin{array}{l}\text { Gürkanlar } \\
\text { et al. [17] }\end{array}$ & $56 / M$ & Bilateral leg pain & $\begin{array}{l}\text { IDEM at L1-L2 with } \\
\text { parital invasion of conus }\end{array}$ & Oligo & TR & NA \\
\hline $\begin{array}{l}\text { Ramirez } \\
\text { et al. [18] }\end{array}$ & $22 / \mathrm{M}$ & $\begin{array}{l}\text { Paresthesia, LBP and left } \\
\text { Brown-Sequard syndrome }\end{array}$ & $\begin{array}{l}\text { IM with hematomyelia } \\
\text { at C5-C7 }\end{array}$ & $\mathrm{AO}$ & $P R$ and $R T$ & 2 years, brain metastasis \\
\hline $\begin{array}{l}\text { Wang } \\
\text { et al. [19] }\end{array}$ & $18 / F$ & $\begin{array}{l}\text { Low back pain, lower limb } \\
\text { weakness, hypalgesia below } \\
\text { level T5 }\end{array}$ & $\begin{array}{l}\text { IM with syringomyelia } \\
\text { at T8-T10 }\end{array}$ & $\mathrm{AO}$ & 1st PR and RT & $\begin{array}{l}-8 \text { months, tumor recurrence- } 2 \text { nd PR and TMZ-1 year after TMZ, } \\
\text { no recurrence of tumor }\end{array}$ \\
\hline $\begin{array}{l}\text { Present } \\
\text { case }\end{array}$ & $46 / M$ & $\begin{array}{l}\text { Neck pain, left arm weakness, } \\
\text { suspended sensory deficit at } \\
\text { C5-T1 levels }\end{array}$ & $\begin{array}{l}\text { IM with syringomyelia } \\
\text { at C3-T4 }\end{array}$ & Oligo & $P R$ and $R T$ & -1 year, tumor recurrence \\
\hline
\end{tabular}


Moreover, TMZ may be an advantage in recurrent situations.

\section{Consent}

Written, informed consent was obtained from the patient for publication of this case report and accompanying images. A copy of the written consent is available for review by the Editor-in-Chief of this journal.

\section{Additional file}

Additional file 1: A video of an intraoperative finding. (MP4 $14804 \mathrm{~kb}$ )

\section{Abbreviations}

MRI: Magnetic resonance imaging; TMZ: Temozolomide.

\section{Competing interests}

The authors declare that they have no competing interests.

\section{Authors' contributions}

TT was a major contributor in the writing the manuscript. TE supervised the whole work. Both authors read and approved the final manuscript.

\section{Acknowledgements}

The immunohistochemical figures referred to in this study are the work of Dr. Kanet Kanjanapadit.

Received: 16 September 2015 Accepted: 26 October 2015

Published online: 18 January 2016

\section{References}

1. Bradl M, Lassmann H. Oligodendrocytes: biology and pathology. Acta Neuropathol. 2010;119:37-53.

2. $\mathrm{Ng} \mathrm{HK}$, Sun DT, Poon WS. Anaplastic oligodendroglioma with drop metastasis to the spinal cord. Clin Neurol Neurosurg. 2002;104:383-6.

3. Carlsen JG, Tietze A, Lassen YA, Rosendal F. Paraplegia due to drop metastases from anaplastic oligodendroglioma. Br J Neurosurg. 2012 26:d94-5

4. Fortuna A, Celli P, Palma L. Oligodendrogliomas of the spinal cord. Acta Neurochir. 1980;52:305-29.

5. Guidetti B, Mercuri S, Vagnozzi R. Long-term results of the surgical treatment of 129 intramedullary spinal gliomas. J Neurosurg. 1981;54:323-30.

6. Alvis C, Cerisoli M, Giulioni M. Intramedullary spinal gliomas: long-term results of surgical treatments. Acta Neurochir (Wien). 1984;70:169-79.

7. Pagni CA, Canavero S, Gaidolfi E. Intramedullary "holocord" oligodendroglioma: case report. Acta Neurochir. 1991;113:96-9.

8. Wang KC, Chi JG, Cho BK. Oligodendroglioma in childhood. J Korean Med Sci. 1993:8:110-6.

9. Cristante L, Herrmann HD. Surgical management of intramedullary spina cord tumor: functional outcome and source of morbidity. Neurosurgery. 1994;35:69-76.

10. Constantini S, Houten J, Miller DC, Freed DF, Ozek MM, Rorke LB. Intramedullary spinal cord tumors in children under the age of 3 years. J Neurosurg. 1996;85:1036-43.

11. Nam DH, Cho BK, Kim YM, Chi JG, Wang KC. Intramedullary anaplastic oligodendroglioma in a child. Childs Nerv Syst. 1998;14:127-30.

12. Ushida T, Sonobe $H$, Mizobuchi $H$, Toda M, Tani T, Yamamoto H. Oligodendroglioma of the "widespread" type in the spinal cord. Childs Nerv Syst. 1998;14:751-5.

13. Gilmer-Hill HS, Ellis WG, Imbesi SG, Boggan JE. Spinal oligodendroglioma with gliomatosis in a child: case report. J Neurosurg. 2000;92:109-13.

14. Miller DC. Surgical pathology of intramedullary spinal cord neoplasms. J Neurooncol. 2000;47:189-94.

15. Aman RA, Padmosantjojo MH, Atmadji LB, Soemitro D. Intramedullary oligodendroglioma: a case report. Gan To Kagaku Ryoho. 2000;27:571-3.
16. Fountas KN, Karampelas I, Nikolakakos LG, Troup EC, Robinson JS. Primary spinal cord oligodendroglioma: case report and review of the literature. Childs Nerv Syst. 2005;21:171-5.

17. Gürkanlar D, Koçak H, Aciduman A, Yucel E, Ekinci O. Primary spinal cord oligodendroglioma. Case illustration. Neurocirugia. 2006;17:542-3.

18. Ramirez C, Delrieu O, Mineo JF, Paradot G, Allaoui M, Dubois F, et al. Intracranial dissemination of primary spinal cord anaplastic oligodendroglioma. Eur J Neurol. 2007;14:578-80.

19. Wang F, Qiao G, Lou X. Spinal cord anaplastic oligodendroglioma with 1p deletion: report of a relapsing case treated with temozolomide. Neurooncol. 2011;104:387-94.

20. Koeller KK, Rosenblum RS, Morrison AL. Neoplasms of the spinal cord and filum terminale: radiologic-pathologic correlation. Radiographics. 2000;20:1721-49.

21. Gan HK, Rosenthal MA, Dowling A, Kalnins R, Algar E, Wong N, et al. A phase II trial of primary temozolomide in patients with grade III oligodendroglial brain tumors. Neuro Oncol. 2010;12:500-7.

\section{Submit your next manuscript to BioMed Central and take full advantage of:}

- Convenient online submission

- Thorough peer review

- No space constraints or color figure charges

- Immediate publication on acceptance

- Inclusion in PubMed, CAS, Scopus and Google Scholar

- Research which is freely available for redistribution

Submit your manuscript at www.biomedcentral.com/submit 